\title{
Safety, effectiveness, and cost effectiveness of long acting versus intermediate acting insulin for patients with type 1 diabetes: systematic review and network meta-analysis
}

\begin{abstract}
Objective To examine the safety, effectiveness, and cost effectiveness of long acting insulin for type 1 diabetes.

Design Systematic review and network meta-analysis.

Data sources Medline, Cochrane Central Register of Controlled Trials, Embase, and grey literature were searched through January 2013.

Study selection Randomized controlled trials or non-randomized studies of long acting (glargine, detemir) and intermediate acting (neutral protamine Hagedorn (NPH), lente) insulin for adults with type 1 diabetes were included.

Results 39 studies (27 randomized controlled trials including 7496 patients) were included after screening of 6501 titles/abstracts and 190 full text articles. Glargine once daily, detemir once daily, and detemir once/twice daily significantly reduced hemoglobin $A_{1 c}$ compared with $\mathrm{NPH}$ once daily in network meta-analysis ( 26 randomized controlled trials, mean difference $-0.39 \%$, $95 \%$ confidence interval $-0.59 \%$ to $-0.19 \% ;-0.26 \%,-0.48 \%$ to $-0.03 \%$; and $-0.36 \%,-0.65 \%$ to $-0.08 \%$; respectively). Differences in network meta-analysis were observed between long acting and intermediate acting insulin for severe hypoglycemia (16 randomized controlled trials; detemir once/twice daily
\end{abstract}

versus $\mathrm{NPH}$ once/twice daily: odds ratio $0.62,95 \%$ confidence interval 0.42 to 0.91 ) and weight gain (13 randomized controlled trials; detemir once daily versus NPH once/twice daily: mean difference $4.04 \mathrm{~kg}, 3.06$ to $5.02 \mathrm{~kg}$; detemir once/twice daily versus NPH once daily: $-5.51 \mathrm{~kg}$, -6.56 to $-4.46 \mathrm{~kg}$; glargine once daily versus NPH once daily: $-5.14 \mathrm{~kg}$, -6.07 to -4.21 ). Compared with NPH, detemir was less costly and more effective in $3 / 14$ cost effectiveness analyses and glargine was less costly and more effective in $2 / 8$ cost effectiveness analyses. The remaining cost effectiveness analyses found that detemir and glargine were more costly but more effective than NPH. Glargine was not cost effective compared with detemir in 2/2 cost effectiveness analyses.

Conclusions Long acting insulin analogs are probably superior to intermediate acting insulin analogs, although the difference is small for hemoglobin $A_{10}$. Patients and their physicians should tailor their choice of insulin according to preference, cost, and accessibility.

Systematic review registration PROSPERO CRD42013003610.

\section{Introduction}

To treat hyperglycemia associated with type 1 diabetes, insulin is administered; isophane insulin (neutral protamine Hagedorn $(\mathrm{NPH})$ ) and zinc insulin (lente) have been used commonly since 
the 1950s. Newer insulin analogs (for example, glargine, detemir) are reported to have a longer duration of action and less between patient variability ${ }^{1}$; they have been available since the early 2000s.

Some evidence suggests that the newer long acting insulin analogs such as glargine and detemir might be more effective and safer than intermediate acting insulin (NPH and lente). ${ }^{2-5}$ Although systematic reviews exist on this topic, ${ }^{2-4}$ only efficacy data from randomized trials were analyzed and comparative effectiveness data from observational studies were not included. Furthermore, cost effectiveness data were not considered in these reviews. ${ }^{2-4}$ We did a systematic review and network meta-analysis to examine the comparative effectiveness, safety, and cost effectiveness of long acting insulin versus intermediate acting insulin for patients with type 1 diabetes.

\section{Methods \\ Protocol}

We developed a systematic review protocol using the Preferred Reporting Items for Systematic reviews and Meta-Analysis for Protocols. ${ }^{6}$ We revised the protocol following feedback from decision makers at the British Columbia Ministry of Health who had posed the query. The final protocol was published and registered with PROSPERO (CRD42013003610). ${ }^{78}$ Our methods are briefly described here.

\section{Eligibility criteria}

We included studies of long acting insulin analogs (glargine and detemir) compared with each other or with intermediate acting insulin (NPH and lente) administered to adults with type 1 diabetes. We excluded studies of pre-mixed insulin preparations. Experimental (randomized clinical trials, quasi-randomized trials, non-randomized trials), quasi-experimental (interrupted time series, controlled before and after study), and observational (cohort) study designs were eligible for inclusion.

We worked with decision makers from the British Columbia Ministry of Health to select the outcomes that were most relevant to them. ${ }^{7}$ The primary outcome was glycated hemoglobin $\left(\mathrm{A}_{1 \mathrm{c}}\right)$; secondary outcomes included severe hypoglycemia (as defined by the authors), serious hyperglycemia (as defined by the authors), weight gain, quality of life, microvascular complications, macrovascular complications, all cause mortality, incident cancers, and cost effectiveness. We imposed no restrictions related to publication status or date, and we attempted to translate non-English articles.

\section{Literature search}

The literature search included Medline, Embase, and the Cochrane Central Register of Controlled Trials, supplemented by searching trial registry websites, conference abstracts, and the reference lists of included studies and relevant reviews. ${ }^{2-4}$ We did forward citation searching in Web of Science and searched the 10 most relevant citations in PubMed for all studies fulfilling our eligibility criteria. The Medline search was peer reviewed and published previously. ${ }^{79}$ The other search strategies can be obtained from the authors on request. All searches were executed on January 8, 2013.

\section{Screening}

After a calibration exercise, two reviewers (ACT, HA, CS, AH, CW, ST, GS) independently screened each citation and subsequent full text article. Conflicts were resolved by discussion for all levels of screening.

\section{Data items}

We abstracted data for characteristics of studies and patients and for outcome results. For cost effectiveness studies, data items included study characteristics (for example, intervention, comparator, perspective, currency) and results (for example, incremental cost effectiveness ratios, cost per quality adjusted life year, cost per life year). We derived incremental cost effectiveness ratios for studies reporting the difference in both effectiveness and cost between the intervention and control groups by using the following formula: (cost of the intervention-cost of the comparator)/(effectiveness of the intervention-effectiveness of the comparator). ${ }^{10}$

\section{Data abstraction and quality/risk of bias appraisal}

We appraised quality and risk of bias by using the Cochrane risk of bias tool for randomized controlled trials, ${ }^{11}$ the Newcastle-Ottawa scale for cohort studies, ${ }^{12}$ and a 10 item tool developed by Drummond and colleagues for cost effectiveness studies. ${ }^{10}$ We used the McHarm tool to examine the reporting of adverse drug reactions in the studies that reported harms. ${ }^{13}$ After calibration of the data abstraction process, two team members (HA, JA, CS, AH, CW) independently abstracted and appraised each of the included studies. Conflicts were resolved by discussion. We contacted authors for missing data or clarifications. Finally, two team members (ACT, HA) reviewed all data to ensure accuracy before analysis.

\section{Synthesis}

We did random effects pairwise meta-analysis using the odds ratio effect measure for dichotomous data and the mean difference for continuous data, when at least two studies examined the same intervention and comparator for a particular outcome. For dichotomous outcomes in which studies reported 0 events in one treatment arm, we added 0.5 to the numerator and 1 to the denominator. Studies reporting 0 events in all treatment arms for a particular outcome were excluded from the analysis.

When sufficient data were available (that is, at least five studies reported the same outcome with most relevant treatment comparisons examined), we did random effects network meta-analysis. We summarized the evidence by using a network diagram for each outcome. We assumed a common within network estimate for heterogeneity and estimated it with the restricted maximum likelihood method. ${ }^{14} \mathrm{We}$ assessed the transitivity assumption by examining the comparability of the distribution of the treatment effect modifiers across comparisons, ${ }^{15}$ including hemoglobin $\mathrm{A}_{1 \mathrm{c}}$ levels $(<8 \% v \geq 8 \%)$, crossover trials, pregnancy, and quality of studies according to the Cochrane risk of bias tool. ${ }^{11}$ We evaluated whether consistency existed between direct and indirect evidence, and between studies involving different sets of treatments for the same comparison, by using the design by treatment interaction model for the network. ${ }^{16}$ We assessed inconsistency locally in the network by using the loop specific method. ${ }^{17}$ We used sub-group and sensitivity analysis to explore important network inconsistency.

We calculated the network meta-analysis summary treatment effects with their $95 \%$ confidence intervals and $95 \%$ predictive intervals. We calculated the predictive intervals for the summary treatment effects to capture their uncertainty and the magnitude 
of the heterogeneity in the network. ${ }^{18}$ The predictive intervals provide intervals within which the estimated treatment effect of a future study is expected to lie. ${ }^{19}$ To visually assess the presence of heterogeneity, small study effects, and bias (including publication bias) in the network, we applied the comparison adjusted funnel plot. ${ }^{18}$ To account for the fact that each study estimates the relative effect of different treatments, we ordered the treatments from oldest to newest, and we used the fixed effects model, as the random effects model is more affected by small study effects. We used the surface under the cumulative ranking curve to rank the treatments. ${ }^{20} \mathrm{We}$ did pairwise meta-analysis with the metafor package in $\mathrm{R}$ software and network meta-analysis by using the method of multivariate meta-analysis in Stata with the mvmeta command. ${ }^{21} 22$

We considered NPH administered twice daily to be usual care (that is, the reference standard). We grouped treatments into nodes with input from clinicians and examined the robustness of the selected treatment nodes by sensitivity analysis.

Specifically, we entered the insulin analogs separately in the analysis without considering daily frequency (glargine versus detemir versus NPH) and then with daily frequency (glargine once daily, glargine twice daily, and so on).

To compare the economic results across the cost effectiveness studies, we converted costing data to 2012 international United States dollars (USD). All costs were converted to US dollars and adjusted for inflation by using the consumer price index for medical care in the United States. ${ }^{23} 24$

\section{Results}

\section{Literature search}

The literature search yielded a total of 6501 titles and abstracts (fig $1 \Downarrow$ ). Thirty nine studies fulfilled the eligibility criteria, including 38 primary publications ${ }^{5-61}$ and one companion report. ${ }^{62}$

\section{Characteristics of studies and patients}

One study was written in Serbian, ${ }^{33}$ one was a trial protocol that reported unpublished results, ${ }^{34}$ and another was a conference abstract that reported cost effectiveness results. ${ }^{56}$ Twenty seven studies were randomized controlled trials with study durations ranging from 4 to 104 weeks and including 7496 patients (table $1 \Downarrow) .{ }^{25-51}$ Most of the randomized controlled trials were multicenter, were conducted in Europe or North America, and examined glargine versus NPH (10 trials), detemir versus NPH (11 trials), or detemir versus glargine (3 trials). At baseline, the proportion of female participants ranged from $21 \%$ to $100 \%$ (in a study of pregnant women) (appendix 7). The mean age ranged from 28 to 47 years, mean body mass index from 23.1 to 28.0 , hemoglobin $\mathrm{A}_{1 \mathrm{c}}$ from $6.9 \%$ to $9.5 \%$, and duration of type 1 diabetes from 11 to 27 years. One study was a cohort with more than 14 years of follow-up. More than 3100 patients with type 1 diabetes were included in this study from the United Kingdom, and the effects of glargine versus detemir were examined (table $1 \Downarrow) .^{52}$ Ten of the included publications were cost effectiveness

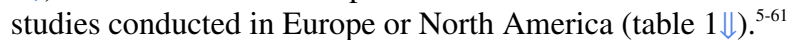

\section{Risk of bias and methodological quality results}

Most of the trials had an unclear risk of bias on three to five of the seven items; 17 randomized controlled trials had a high risk of bias on one to three of the criteria (appendices 1 and 2). Only $41 \%$ of the randomized controlled trials had a low risk of bias for random sequence generation, and approximately $19 \%$ had a low risk of bias on allocation concealment. Twenty randomized controlled trials were funded by drug companies, and some of the authors of these trials were employed by the company funding the study.

Twenty one randomized controlled trials reported on harms associated with treatment and were assessed using the McHarm tool (appendices 3 and 4). ${ }^{13}$ Most randomized controlled trials reported between $7 \%$ and $53 \%$ of the 15 items; two adequately reported more than $60 \%$ of the items. ${ }^{37} 38$

The cohort study fulfilled most of the Newcastle-Ottawa scale criteria. ${ }^{12}{ }^{52}$ However, the authors did not report the number of withdrawals or control for confounders in their analysis (appendix 5). This study was funded by a drug company.

Three cost effectiveness analyses fulfilled all of the methodological quality criteria on the Drummond tool, ${ }^{5-59}$ and four were scored as unclear on one or two of the criteria (appendix 6). ${ }^{54-60}$ One study obtained effectiveness estimates from an observational study, ${ }^{53}$ and another based effectiveness on overall hypoglycemia instead of mild hypoglycemia.$^{54}$ Both were scored as not adequately fulfilling the effectiveness item. One publication was a conference abstract, and $60 \%$ of the items were assessed as being unclear. ${ }^{56}$ Eight studies were funded by a drug company, ${ }^{53-61}$ whereas the source of funding was not reported for two cost effectiveness studies. ${ }^{56}$

\section{Network meta-analysis results Primary outcome-hemoglobin $A_{10}$}

We did a network meta-analysis on hemoglobin $\mathrm{A}_{1 \mathrm{c}}$ that included 26 randomized controlled trials and 6776 patients (appendix 8). ${ }^{25-51}$ After a median of 20 weeks of follow-up, only NPH once daily resulted in a significantly greater hemoglobin $\mathrm{A}_{1 \mathrm{c}}$ compared with NPH once or twice daily (mean difference $0.31 \%, 95 \%$ confidence interval $0.02 \%$ to $0.60 \%$ ) (table $2 \Downarrow$; fig $2 \Downarrow$ ). Glargine once daily (mean difference $-0.39 \%,-0.59 \%$ to $-0.19 \%$ ), detemir once daily $(-0.26 \%,-0.48 \%$ to $-0.03 \%)$, and detemir once or twice daily $(-0.36 \%,-0.65 \%$ to $-0.08 \%)$ resulted in significantly reduced hemoglobin $\mathrm{A}_{1 \mathrm{c}}$ compared with $\mathrm{NPH}$ once daily. However, none of these was statistically significant in our network meta-analysis including predictive intervals. We observed no other statistically significant differences.

On the basis of the surface under the cumulative ranking curve cumulative rankings, glargine once daily had the greatest likelihood of being the most effective insulin in reducing hemoglobin $A_{1 c}$, followed by glargine twice daily, detemir four times a day, and detemir once or twice daily (appendix 16). Similar results were observed in our sensitivity analysis when the treatment nodes were glargine, detemir, and NPH (that is, not incorporating daily dosing). Results for direct and indirect meta-analyses were consistent statistically (table $2 \Downarrow$ ).

We did a sub-group analysis by baseline hemoglobin $\mathrm{A}_{1 \mathrm{c}}$. For patients with poorly controlled hemoglobin $\mathrm{A}_{1 \mathrm{c}}$ (values $\geq 8 \%$ ), the following types of insulin were examined in 12 randomized controlled trials including 4002 patients: NPH once or twice daily, NPH once daily, glargine once daily, detemir once daily, and detemir once or twice daily. Glargine once daily resulted in significantly improved hemoglobin $\mathrm{A}_{1 \mathrm{c}}$ compared with NPH once daily (mean difference $-0.65 \%,-0.96 \%$ to $-0.35 \%$ ) and detemir once daily $(-0.41 \%,-0.74 \%$ to $-0.08 \%)$. Both detemir once or twice daily (mean difference $-0.49 \%,-0.82 \%$ to $-0.16 \%)$ and detemir administered four times daily $(-0.65 \%$, $-1.12 \%$ to $-0.17 \%$ ) significantly reduced hemoglobin $\mathrm{A}_{1 \mathrm{c}}$ compared with NPH once daily. On the basis of the surface under the cumulative ranking curve, glargine once daily had the greatest likelihood of being the most effective insulin in reducing hemoglobin $\mathrm{A}_{1 \mathrm{c}}$. 
For patients with hemoglobin $\mathrm{A}_{1 \mathrm{c}}$ values below $8 \%$, the following types of insulin were examined in 14 randomized controlled trials including 2774 patients: NPH once or twice daily, NPH once daily, NPH four times daily, glargine once daily, glargine twice daily, detemir once daily, and detemir once or twice daily. Glargine once daily significantly improved hemoglobin $\mathrm{A}_{1 \mathrm{c}}$ compared with NPH once daily (mean difference $-0.29 \%,-0.58 \%$ to $-0.01 \%)$. On the basis of the surface under the cumulative ranking curve, detemir once daily had the greatest likelihood of being the most effective insulin in reducing hemoglobin $\mathrm{A}_{1 \mathrm{c}}$, followed by NPH once or twice daily and glargine once daily.

We did another sub-group analysis in which the randomized controlled trial including pregnant women was removed ${ }^{25}$; the same results were observed. We did a sub-group analysis excluding crossover trials and studies with high risk of allocation concealment bias from the network ${ }^{30-49}$; the results did not change. The observational study reported hemoglobin $\mathrm{A}_{1 \mathrm{c}}$ results after 14 years of follow-up, but we were unable to include this study in our network meta-analysis as the authors did not report a variance measure associated with the mean. ${ }^{52}$

\section{Secondary outcome-body weight}

We did a network meta-analysis on body weight, including 13 randomized controlled trials and 3396 patients (appendix 23). ${ }^{26-50}$ After a median of 26 weeks of follow-up, NPH once daily (mean difference $4.64 \mathrm{~kg}, 3.53$ to $5.75 \mathrm{~kg}$ ) and detemir once daily (4.04 $\mathrm{kg}, 3.06$ to $5.02 \mathrm{~kg}$ ) caused significantly more weight gain compared with NPH once or twice daily; however, detemir once or twice daily caused significantly less weight gain than NPH once or twice daily $(-0.87 \mathrm{~kg},-1.44$ to $-0.30 \mathrm{~kg}$ ) (table $2 \Downarrow)$. Patients receiving detemir once or twice daily (mean difference $-5.51 \mathrm{~kg},-6.56$ to $-4.46 \mathrm{~kg})$, detemir once daily $(-0.60 \mathrm{~kg}$, -1.13 to $-0.08 \mathrm{~kg})$, and glargine once daily $(-5.14 \mathrm{~kg},-6.07$ to $-4.21 \mathrm{~kg}$ ) had significantly less weight gain than those receiving NPH once daily. Furthermore, detemir once daily caused significantly more weight gain than detemir once or twice daily (mean difference $4.91 \mathrm{~kg}, 4.00$ to $5.81 \mathrm{~kg}$ ) and glargine once daily caused significantly less weight gain than detemir once daily $(-4.54 \mathrm{~kg},-5.30$ to $-3.77 \mathrm{~kg})$. Our network meta-analysis including the predictive intervals showed similar results, except that results for detemir once or twice daily versus NPH once or twice daily and detemir once daily versus NPH once daily were no longer significant. According to the surface under the cumulative ranking curve, detemir once or twice daily had the greatest probability of causing the least amount of weight gain, followed by glargine once daily. The design by treatment interaction model suggested no inconsistency in the network as a whole. Our sub-group analysis that removed crossover trials produced the same results. ${ }^{26}{ }^{32} \mathrm{We}$ were unable to include the observational study in the network meta-analysis because the authors did not report a variance measure associated with the mean body weight. ${ }^{52}$

\section{Secondary outcome-severe hypoglycemia}

We did a network meta-analysis on the number of patients experiencing severe hypoglycemia, which included 16 randomized controlled trials and 5697 patients (appendix 33). ${ }^{25-50}$ The definition of severe hypoglycemia varied across the studies (appendix 36). After a median of 24 weeks of follow-up, patients receiving detemir once or twice daily experienced significantly less severe hypoglycemia than those receiving NPH once or twice daily (odds ratio $0.62,95 \%$ confidence interval 0.42 to 0.91 ) (table $2 \Downarrow$ ). However, this was no longer statistically significant in our network meta-analysis including the predictive intervals. Glargine twice daily and detemir once daily had the greatest likelihood of causing the least severe hypoglycemia according to the surface under the cumulative ranking curve. Statistical inconsistency was observed in the network as a whole despite several sub-group and sensitivity analyses, including removing the randomized controlled trial including pregnant women $^{25}$ or crossover trials. ${ }^{26-38}$ Inconsistency was no longer statistically significant when three randomized controlled trials with high risk of bias were excluded. ${ }^{30-49}$ After this exercise, we found the same results for detemir once or twice daily versus $\mathrm{NPH}$ once or twice daily. However, detemir administered four times daily caused significantly more patients to experience severe hypoglycemia compared with detemir once or twice daily (odds ratio 3.09, 1.31 to 7.27 ) or glargine once daily $(1.69,1.12$ to 2.50 ). The same results were observed with the surface under the cumulative ranking curve, and similar results were observed in our sensitivity analysis of treatment nodes.

\section{Direct comparisons meta-analysis and single point estimate results}

\section{Secondary outcome-number of patients experiencing serious hyperglycemia}

One randomized controlled trial reported serious hyperglycemic events, which were not defined. After 26 weeks of follow-up, no statistically significant difference existed between detemir twice daily and NPH twice daily (relative risk 5.74, 0.23 to 140.48). ${ }^{44}$

\section{Secondary outcome-microvascular complications}

Three randomized controlled trials reported retinopathy, but all examined different insulin treatments. No statistically significant differences were observed for glargine twice daily versus NPH twice daily after 16 weeks of follow-up (relative risk 1.28, 0.48 to 3.40$),{ }^{49}$ detemir twice daily versus NPH twice daily after 24 weeks of follow-up $(0.89,0.43$ to 1.86$),{ }^{25}$ and detemir twice daily versus NPH twice daily after 26 weeks of follow-up (1.62, 0.66 to 3.93$).^{45}$

\section{Secondary outcome-macrovascular complications}

One randomized controlled trial reported transient ischemic attack after 16 weeks of follow-up. ${ }^{41}$ No statistically significant difference was observed between detemir twice daily and NPH twice daily (relative risk $2.93,0.12$ to 71.33 ). One randomized controlled trial reported death due to myocardial infarction and found no statistically significant differences between detemir once daily and NPH once daily after 32 weeks of follow-up (relative risk 4.47, 0.24 to 82.58), ${ }^{38}$ and another found similar results for death due to cardiopulmonary arrest for glargine once daily versus NPH twice daily after 28 weeks of follow-up $(0.34$, 0.01 to 8.33$){ }^{50}$

\section{Secondary outcome-all cause mortality}

After a median of 24 weeks of follow-up, no a statistically significant difference was observed between detemir twice daily and NPH twice daily for all cause mortality (two randomized controlled trials; odds ratio $0.97,0.10$ to $\left.9.44 ; \mathrm{I}^{2}=0 \%\right) .{ }^{38}$ Five randomized controlled trials reported 0 deaths in both arms for detemir once daily versus glargine once daily, ${ }^{26}$ glargine twice daily versus glargine once daily, ${ }^{37}$ detemir once daily versus NPH twice daily, ${ }^{25}{ }^{34}$ and glargine once daily versus NPH twice daily, ${ }^{49}$ so they were not included in the meta-analysis. 


\section{Secondary outcome-incident cancer}

After 16 weeks of follow-up, no statistically significant difference was observed between glargine once daily and NPH twice daily for pancreatic cancer (relative risk $0.33,0.01$ to 8.12). ${ }^{49}$ Similarly, after 26 weeks of follow-up, no statistically significant difference was observed between detemir twice daily and NPH twice daily for uterine cancer (relative risk 1.46, 0.06 to 35.63$).^{47}$

\section{Secondary outcome-quality of life}

After 24 weeks of follow-up, quality of life did not differ between glargine once daily (median 32, interquartile range 27-34) and NPH twice daily (median 31, interquartile range 25-34) on the Well-Being Enquiry for Diabetics questionnaire in one randomized controlled trial. ${ }^{31}$

\section{Secondary outcome-cost effectiveness}

Fourteen cost effectiveness analyses reported in five studies compared detemir with NPH (table $3 \Downarrow$ ). ${ }^{5-58}$ Three of these analyses found that detemir was less costly and more effective,${ }^{54-57}$ and the others found that detemir was more costly but also more effective than NPH. Eight cost effectiveness analyses reported in five studies compared glargine with $\mathrm{NPH}{ }^{53-60}$ Glargine was less costly and more effective in two of these analyses, ${ }^{53}$ and six found that glargine was more costly and more effective than NPH. Compared with detemir, glargine was not cost effective in either analysis examining this comparison. ${ }^{61}$

\section{Discussion}

We found that glargine once daily, detemir once daily, and detemir twice daily significantly reduced hemoglobin $\mathrm{A}_{1 \mathrm{c}}$ compared with NPH once daily in our network meta-analysis. Given the small reduction in hemoglobin $\mathrm{A}_{\mathrm{lc}}$ observed, no differences are likely to be clinically relevant because they did not approach the commonly accepted $0.5 \%$ minimal clinically important difference in hemoglobin $\mathrm{A}_{1 \mathrm{c}}$. Furthermore, none of the treatment comparisons was statistically significant in our network meta-analysis including the predictive intervals, suggesting that the estimates are probably unstable and that any treatment may be effective in a future study. Of note, glargine once daily was significantly superior to NPH once daily overall and in our sub-group analysis on baseline values of hemoglobin $A_{1 c}$. Glargine once daily was also more effective for patients with poorly controlled diabetes (those with hemoglobin $\mathrm{A}_{1 \mathrm{c}}$ $\geq 8 \%$ ) than those with hemoglobin $\mathrm{A}_{\mathrm{lc}}$ below $8 \%$. Many of our results comparing weight gain for long acting and intermediate acting insulin were clinically relevant. NPH once daily and detemir once daily caused more weight gain than NPH once or twice daily. Detemir once or twice daily and glargine once daily caused significantly less weight gain than NPH once daily. Also, patients receiving detemir once or twice daily experienced significantly less hypoglycemia compared with those receiving NPH once or twice daily. The cost effectiveness analysis results were inconsistent across studies. In aggregate, our findings suggest that in terms of glycemic control, long acting insulin analogs are slightly superior to intermediate acting insulin analogs; in terms of safety, long acting insulin analogs are associated with slightly less weight gain and fewer episodes of severe hypoglycemia.

\section{Strengths and weaknesses in relation to other studies, discussing important differences in results}

In a previous systematic review and network meta-analysis, Sanches and colleagues concluded that detemir and glargine were not clinically different from NPH for glycemic control or safety, whereas we found that long acting insulin analogs are slightly superior to intermediate acting insulin analogs for glycemic control. ${ }^{3}$ We also found that harms (weight gain and severe hypoglycemia) occurred less often for patients receiving long acting versus intermediate acting insulins. In addition, we included five randomized controlled trials including 1028 patients (probably owing to our later search date), one cohort study, and 10 cost effectiveness studies that have never been included in any of the previous systematic reviews in this area (appendices 37 and 38). ${ }^{2-63}$

The reported methods of the randomized controlled trials included in our review could be strengthened by using an adequate method of randomization (for example, computer generated), conducting appropriate allocation concealment (for example, centralized randomization), and adequately reporting harms outcomes. Furthermore, the definitions of severe hypoglycemia varied across studies, and studies were limited further by lack of reporting of the dosages of insulin administered to the patients. The randomized controlled trials could be strengthened by a longer duration of follow-up, as the average duration of follow-up ranged from 16 to 26 weeks. This is of particular importance for the all cause mortality and incident cancer outcomes, which require longer durations of follow-up for events to occur. This major shortcoming means that our results should be interpreted with caution. The cohort study that was included could be strengthened by reporting estimates of variance and number of withdrawals, controlling for confounders in the analysis, and examining harms outcomes. Another limitation is that variation exists in the bioavailability of the different types of insulin. For example, larger doses of insulin detemir are required compared with glargine or NPH, increasing the cost of detemir. None of the included cost effectiveness analyses adequately addressed the question of dosages required. Finally, the cost effectiveness analyses included in our review could be improved by using appropriate effectiveness estimates (for example, from randomized trials) and reporting the source of funding.

Our systematic review process also has limitations. We excluded a randomized controlled trial written in Japanese, ${ }^{64}$ as we were unable to translate the study, and some of our results were only based on one included study (for example, retinopathy, quality of life) and should be interpreted with caution. Finally, we focused on cost effectiveness results that were dominant (less costly, more effective). However, many of the included cost effectiveness analyses found that detemir was more costly and more effective than NPH and that glargine was more costly and more effective than NPH. In these cases, the cost effectiveness of the insulin analog will depend on the decision makers' willingness to pay. Moreover, the cost variable in each analysis included the cost of treatment and additional costs, depending on the perspective of the analysis (see table $3 \Downarrow$ ).

In addition, network meta-analysis is complex and can be difficult for decision makers to interpret. For example, in our surface under the cumulative ranking curve analysis for weight, detemir once or twice daily was the intervention with the greatest likelihood of ranking. This is because of the large and precise effect size that favors the particular intervention but also the network structure. Each direct estimate contributes differently to the network meta-analysis estimation depending on the 
information it provides. The NPH once or twice daily versus detemir once or twice daily comparison includes the greatest number and size of studies, and a small variance, which can highly influence the neighboring comparisons via the indirect comparison. The contribution of each comparison to the network summary effects can affect the significance or the validity of the results. For instance, excluding the poor quality studies in the same network did not affect the results, because these studies had a low contribution to the network. This might not be an intuitive finding, as detemir once or twice daily was not statistically significantly superior to all agents. Also, our network meta-analysis results are limited by the minimal evidence available resulting in sparse network configurations, which was especially apparent for the body weight outcome. Furthermore, we were unable to include non-randomized evidence in our network meta-analysis of glycemic control and body weight, owing to missing measures of variance.

\section{Meaning of study: possible explanations and implications for clinicians and policy makers}

Long acting insulin analogs are probably superior to intermediate acting insulin analogs for some outcomes, although the difference is small for hemoglobin $\mathrm{A}_{1 \mathrm{c}}$. Patients and their physicians should tailor their choice of long acting insulin according to their preference, cost, and accessibility.

\section{Unanswered questions and future research}

Future trials with a sufficient number of patients and longer duration of follow-up should be developed to specifically examine long acting versus intermediate acting insulin for patients with type 1 diabetes. A cost effectiveness analysis comparing all of these interventions would allow policy makers the opportunity to select the type of insulin that is most cost effective.

We thank the British Columbia Ministry of Health for requesting this systematic review and for their useful feedback on the review conception. We thank Laure Perrier for doing the literature searches, Becky Skidmore for peer reviewing the Medline search strategy, and Alissa Epworth for doing the forward citation scanning and the PubMed related article searches. Finally, we thank Maggie Chen for providing feedback on our original proposal; Kednapa Thavorn for appraising the quality of cost effectiveness studies; Judy Tran for locating full text articles; Geetha Sanmugalingham for screening some titles and abstracts; Wing Hui for scanning the reference lists of some included studies, helping to generate the data tables, and formatting the manuscript; and Wasifa Zarin for helping to reformat the paper.

Contributors: ACT conceived and designed the study, helped to obtain funding for the study, screened literature for inclusion, abstracted data from included studies, and wrote the manuscript. HMA coordinated the study, screened the literature search results, and abstracted data. JB, $A A V$, and $W I$ analyzed the results and helped to draft sections of the paper. AH, CS, CW, JA, and ST helped to screen the literature and/or abstracted data. $\mathrm{CHY}, \mathrm{BH}, \mathrm{BRH}, \mathrm{DM}$, and SRM helped to obtain funding for the study and to conceive the study. SES conceived and designed the study, obtained the funding, and helped to write the draft paper. All authors interpreted the results and read, edited, and approved the final paper. SES is the guarantor.

Funding: This systematic review was funded by the Canadian Institutes for Health Research/Drug Safety and Effectiveness Network (CIHR/DSEN). The study funder had no role in the design, conduct, analysis, and decision to submit for publication. ACT and $\mathrm{BH}$ are funded by CIHR/DSEN new investigator awards in knowledge synthesis. JB holds the John $D$ Cameron endowed chair in the genetic determinants of chronic diseases, Department of Clinical Epidemiology and Biostatistics, McMaster University. DM is funded by a University of Ottawa Research chair. SRM is the endowed chair in patient health management (supported by the Faculties of Medicine and Dentistry and Pharmacy and Pharmaceutical Sciences) and holds a health scholar salary award (supported by Alberta Heritage Foundation for Medical Research and Alberta Innovates - Health Solutions). SES is funded by a tier 1 Canada research chair in knowledge translation.

Competing interests: All authors have completed the ICMJE uniform disclosure form at www.icmje.org/coi_disclosure.pdf (available on request from the corresponding author) and declare: this was work funded by the Canadian Institutes for Health Research; no financial relationships with any organization that might have an interest in the submitted work in the previous three years; no relationships or activities that could appear to have influenced the submitted work.

Ethics approval: Not needed.

Declaration of transparency: The lead author (study guarantor) affirms that this manuscript is an honest, accurate, and transparent account of the study being reported; that no important aspects of the study have been omitted; and that any discrepancies from the study as planned (and, if relevant, registered) have been explained.

Data sharing: The data set and literature search are available from the corresponding author at Sharon.straus@utoronto.ca.

1 Valensi $\mathrm{P}$, Cosson $\mathrm{E}$. Is insulin detemir able to favor a lower variability in the action of injected insulin in diabetic subjects? Diabetes Metab 2005;31:4S34-9

2 Monami M, Marchionni N, Mannucci E. Long-acting insulin analogues vs. NPH human insulin in type 1 diabetes: a meta-analysis. Diabetes Obes Metab 2009;11:372-8.

3 Sanches AC, Correr CJ, Venson R, Pontarolo R. Revisiting the efficacy of long-acting insulin analogues on adults with type 1 diabetes using mixed-treatment comparisons. Diabetes Res Clin Pract 2011;94:333-9.

4 Vardi M, Jacobson E, Nini A, Bitterman $\mathrm{H}$. Intermediate acting versus long acting insulin for type 1 diabetes mellitus. Cochrane Database Syst Rev 2008;3:CD006297.

5 Cameron CG, Bennett HA. Cost-effectiveness of insulin analogues for diabetes mellitus. CMAJ 2009;180:400-7.

6 Moher D, Shamseer L, Clarke M, Ghersi D, Liberati A, Petticrew M. Reporting guidelines for systematic review protocols. 9th Cochrane Colloquium, Madrid, Spain, 2011.

7 Tricco AC, Ashoor HM, Soobiah C, Hemmelgarn B, Moher D, Hutton B, et al. Safety, effectiveness, and cost of long-acting versus intermediate-acting insulin for type 1 diabetes: protocol for a systematic review and network meta-analysis. Syst Rev 2013;2(1):73.

8 Tricco A, Ashoor H, Soobiah C, Hemmelgarn B, Moher D, Hutton B, et al. Safety, effectiveness, and cost of long acting versus intermediate acting insulin for type 1 diabetes: protocol for a systematic review and network meta-analysis. 2013. www.crd.york.ac.uk/ PROSPERO/display_record.asp?ID=CRD42013003610\#.UswY29JDt70.

9 Sampson M, McGowan J, Cogo E, Grimshaw J, Moher D, Lefebvre C. An evidence-based practice guideline for the peer review of electronic search strategies. $J$ Clin Epidemiol 2009;62:944-52.

10 Drummond MF, Sculpher MJ, Torrance GW, O'Brien BJ, Stoddart GL. Methods for economic health evaluation of health care programmes. 3rd ed. Oxford University Press, 2005.

11 Higgins JP, Altman DG, Gotzsche PC, Jüni P, Moher D, Oxman AD, et al. The Cochrane Collaboration's tool for assessing risk of bias in randomised trials. BMJ 2011;343:d5928.

12 Wells GA, Shea B, O'Connell D, Peterson J, Welch V, Losos M, et al. The Newcastle-Ottawa Scale (NOS) for assessing the quality if nonrandomized studies in meta-analyses. www.ohri.ca/programs/clinical_epidemiology/oxford.htm.

13 Santaguida PL, Raina P. McMaster Quality Assessment Scale of Harms (McHarm) for primary studies. 2008. www.docstoc.com/docs/32000309/McMaster-Quality-AssessmentScale-of-Harms-_McHarm_-for-primary.

14 Raudenbush SW. Analyzing effect sizes: random effects models. In: Cooper HM, Hedges LV, Valentine JC, eds. The handbook of research synthesis and meta-analysis. 2nd ed. Russell Sage Foundation, 2009:295-315

15 Salanti G. Indirect and mixed-treatment comparison, network, or multiple-treatments meta-analysis: many names, many benefits, many concerns for the next generation evidence synthesis tool. Res Synth Method 2012;3:80-97.

16 White IR, Barrett JK, Jackson D, Higgins JPT. Consistency and inconsistency in network meta-analysis: model estimation using multivariate meta-regression. Res Synth Method 2012;3:111-25.

17 Song F, Altman DG, Glenny AM, Deeks JJ. Validity of indirect comparison for estimating efficacy of competing interventions: empirical evidence from published meta-analyses. BMJ 2003;326:472.

18 Chaimani A, Higgins JP, Mavridis D, Spyridonos P, Salanti G. Graphical tools for network meta-analysis in STATA. PloS One 2013;8:e76654.

19 Riley RD, Higgins JP, Deeks JJ. Interpretation of random effects meta-analyses. BMJ 2011;342:d549.

20 Salanti G, Ades AE, loannidis JP. Graphical methods and numerical summaries for presenting results from multiple-treatment meta-analysis: an overview and tutorial. J Clin Epidemiol 2011;64:163-71.

21 Viechtbauer W. Conducting meta-analyses in R with the metafor package. J Stat Softw 2010;36(3):1-48.

22 White IR. Multivariate random-effects meta-regression: updates to mvmeta. Stata J 2011;11:255-70.

23 OANDA. Historical exchange rates. 2013. www.oanda.com/currency/historical-rates/.

24 United States Department of Labor. Consumer price index. 2013. www.bls.gov/cpi/. 


\section{What is already known on this topic}

Newer long acting insulin analogs might be more effective and safer than intermediate acting insulin in patients with type 1 diabetes but are more expensive

Previous systematic reviews have not included data from observational studies or economic analyses

\section{What this study adds}

This systematic review and network meta-analysis includes five randomized controlled trials (with 1028 patients), one cohort study, and 10 cost effectiveness studies that have never been included in a previous systematic review or network meta-analysis

In patients with type 1 diabetes, long acting insulin is statistically significantly superior to intermediate acting insulin for glycemic control and harms (weight gain and severe hypoglycemia)

The cost effectiveness of intermediate acting and long acting insulins varied across the included cost effectiveness analyses, but glargine and detemir are more costly than neutral protamine Hagedorn (NPH) in most cases

25 Mathiesen ER, Hod M, Ivanisevic M, Duran Garcia S, Brøndsted L, Jovanovic L, et al. Maternal efficacy and safety outcomes in a randomized, controlled trial comparing insulin detemir with NPH insulin in 310 pregnant women with type 1 diabetes. Diabetes Care 2012;35:2012-7.

26 Renard E, Dubois-Laforgue D, Guerci B, for the Variability Study Group. Non-inferiority of insulin glargine versus insulin detemir on blood glucose variability in type 1 diabetes patients: a multicenter, randomized, crossover study. Diabetes Technol Ther 2011;13:1213-8.

27 Zachariah S, Sheldon B, Shojaee-Moradie F, Jackson NC, Backhouse K, Johnsen S, et al. Insulin detemir reduces weight gain as a result of reduced food intake in patients with type 1 diabetes. Diabetes Care 2011;34:1487-91.

28 Heller S, Koenen C, Bode B. Comparison of insulin detemir and insulin glargine in a basal-bolus regimen, with insulin aspart as the mealtime insulin, in patients with type 1 diabetes: a 52-week, multinational, randomized, open-label, parallel-group, treat-to-target noninferiority trial. Clinical Ther 2009;31:2086-97.

29 Le Floch JP, Levy M, Mosnier-Pudar H, Nobels F, Laroche S, Gonbert S, et al. Comparison of once- versus twice-daily administration of insulin detemir, used with mealtime insulin aspart, in basal-bolus therapy for type 1 diabetes: assessment of detemir administration in a progressive treat-to-target trial (ADAPT). Diabetes Care 2009;32:32-7.

30 Bartley PC, Bogoev M, Larsen J, Philotheou A. Long-term efficacy and safety of insulin detemir compared to neutral protamine Hagedorn insulin in patients with type 1 diabetes using a treat-to-target basal-bolus regimen with insulin aspart at meals: a 2-year, randomized, controlled trial. Diabet Med 2008:25:442-9.

31 Bolli GB, Songini M, Trovati M, Del Prato S, Ghirlanda G, Cordera R, et al. Lower fasting blood glucose, glucose variability and nocturnal hypoglycaemia with glargine vs NPH basal insulin in subjects with type 1 diabetes. Nutr Metab Cardiovasc Dis 2009;19:571-9.

32 Chatterjee S, Jarvis-Kay J, Rengarajan T, Lawrence IG, McNally PG, Davies MJ. Glargine versus NPH insulin: efficacy in comparison with insulin aspart in a basal bolus regimen in type 1 diabetes-the glargine and aspart study (GLASS) a randomised cross-over study. Diabetes Res Clin Pract 2007;77:215-22.

33 Pesic M, Zivic S, Radenkovic S, Velojic M, Dimic D, Antic S. [Comparison between basal insulin glargine and NPH insulin in patients with diabetes type 1 on conventional intensive insulin therapy] [Serbian]. Vojnosanit Pregl 2007;64:247-52.

34 Philippo H, Novo Nordisk. Efficacy and safety of insulin detemir in type 1 diabetes. 2007. www.clinicaltrials.gov/ct2/show/study/NCT00595374.

35 Pieber TR, Treichel HC, Hompesch B, Philotheou A, Mordhorst L, Gall MA, et al. Comparison of insulin detemir and insulin glargine in subjects with type 1 diabetes using intensive insulin therapy. Diabet Med 2007;24:635-42.

36 Radman M, Jurisic D, Ljutic D, Jerkovic R, Kovacic N, Hozo IS. Assessing glycemia in type 1 diabetic patients using a microdialysis system for continuous glucose monitoring. Ann Saudi Med 2007;27:166-70.

37 Ashwell SG, Gebbie J, Home PD. Twice-daily compared with once-daily insulin glargine in people with type 1 diabetes using meal-time insulin aspart. Diabet Med 2006;23:879-86.

38 Kolendorf K, Ross GP, Pavlic-Renar I, Perriello G, Philotheou A, Jendle J, et al. Insulin detemir lowers the risk of hypoglycaemia and provides more consistent plasma glucose levels compared with NPH insulin in type 1 diabetes. Diabet Med 2006;23:729-35.

39 De Leeuw I, Vague P, Selam JL, Skeie S, Lang H, Draeger E, et al. Insulin detemir used in basal-bolus therapy in people with type 1 diabetes is associated with a lower risk of nocturnal hypoglycaemia and less weight gain over 12 months in comparison to NPH insulin. Diabetes Obes Metab 2005;7:73-82.

40 Fulcher GR, Gilbert RE, Yue DK. Glargine is superior to neutral protamine Hagedorn for improving glycated haemoglobin and fasting blood glucose levels during intensive insulin therapy. Intern Med J 2005;35:536-42.

41 Pieber TR, Draeger E, Kristensen A, Grill V. Comparison of three multiple injection regimens for type 1 diabetes: morning plus dinner or bedtime administration of insulin detemir vs. morning plus bedtime NPH insulin. Diabet Med 2005;22:850-7.

42 Home P, Bartley P, Russell-Jones D, Hanaire-Broutin H, Heeg JE, Abrams P, et al. Insulin detemir offers improved glycemic control compared with NPH insulin in people with type 1 diabetes: a randomized clinical trial. Diabetes Care 2004;27:1081-7.

43 Porcellati F, Rossetti P, Pampanelli S, Fanelli CG, Torlone E, Scionti L, et al. Better long-term glycaemic control with the basal insulin glargine as compared with NPH in patients with type 1 diabetes mellitus given meal-time lispro insulin. Diabet Med 2004;21:1213-20

44 Russell-Jones D, Simpson R, Hylleberg B, Draeger E, Bolinder J. Effects of QD insulin detemir or neutral protamine Hagedorn on blood glucose control in patients with type diabetes mellitus using a basal-bolus regimen. Clin Ther 2004:26:724-36.

45 Standl E, Lang H, Roberts A. The 12-month efficacy and safety of insulin detemir and $\mathrm{NPH}$ insulin in basal-bolus therapy for the treatment of type 1 diabetes. Diabetes Technol Ther 2004;6:579-88

46 Rossetti P, Pampanelli S, Fanelli C, Porcellati F, Costa E, Torlone E, et al. Intensive replacement of basal insulin in patients with type 1 diabetes given rapid-acting insulin analog at mealtime: a 3-month comparison between administration of NPH insulin four times daily and glargine insulin at dinner or bedtime. Diabetes Care 2003;26:1490-6.

47 Vague P, Selam JL, Skeie S, De Leeuw I, Elte JW, Haahr H, et al. Insulin detemir is associated with more predictable glycemic control and reduced risk of hypoglycemia than $\mathrm{NPH}$ insulin in patients with type 1 diabetes on a basal-bolus regimen with premeal insulin aspart. Diabetes Care 2003;26:590-6.

48 Pieber TR, Eugene-Jolchine I, Derobert E. Efficacy and safety of HOE 901 versus NPH insulin in patients with type 1 diabetes. Diabetes Care 2000;23:157-62.

49 Raskin P, Klaff L, Bergenstal R, Halle JP, Donley D, Mecca T. A 16-week comparison of the novel insulin analog insulin glargine (HOE 901) and NPH human insulin used with insulin lispro in patients with type 1 diabetes. Diabetes Care 2000:23:1666-71.

50 Ratner RE, Hirsch IB, Neifing JL, Garg SK, Mecca TE, Wilson CA. Less hypoglycemia with insulin glargine in intensive insulin therapy for type 1 diabetes. Diabetes Care 2000;23:639-43.

51 Rosenstock J, Park G, Zimmerman J, for the U.S. Insulin Glargine (HOE 901) Type 1 Diabetes Investigator Group. Basal insulin glargine (HOE 901) versus NPH insulin in patients with type 1 diabetes on multiple daily insulin regimens. Diabetes Care 2000;23:1137-42.

52 Currie CJ, Poole CD, Tetlow T, Holmes P, McEwan P. The outcome of care in people with type 1 and type 2 diabetes following switching to treatment with either insulin glargine or insulin detemir in routine general practice in the UK: a retrospective database analysis. Curr Med Res Opin 2007;23(s1):S33-9.

53 Pfohl M, Schadlich PK, Dippel FW, Koltermann KC. Health economic evaluation of insulin glargine vs NPH insulin in intensified conventional therapy for type 1 diabetes in Germany. $J$ Med Econ 2012;15(suppl 2):14-27

54 Valentine WJ, Jendle J, Saraheimo M, Thorsteinsson B, Pollock RF, Lammert M Evaluating the cost-effectiveness of reduced mild hypoglycaemia in subjects with type 1 diabetes treated with insulin detemir or NPH insulin in Denmark, Sweden, Finland and the Netherlands. Diabet Med 2012;29:303-12.

55 Valentine WJ, Aagren M, Haglund M, Ericsson A, Gschwend MH. Evaluation of the long-term cost-effectiveness of insulin detemir compared with neutral protamine hagedorn insulin in patients with type 1 diabetes using a basal-bolus regimen in Sweden. Scand $J$ Public Health 2011;39:79-87.

56 Greiner RA, Azoulay M, Brandle M. Cost-effectiveness of insulin glargine versus NPH insulin for the treatment of type 1 and type 2 diabetes modeling the interaction between hypoglycemia and glycemic control in Switzerland. 69th American Diabetes Association (ADA) Scientific Sessions, New Orleans, Louisiana, 2009.

57 Gschwend MH, Aagren M, Valentine WJ. Cost-effectiveness of insulin detemir compared with neutral protamine Hagedorn insulin in patients with type 1 diabetes using a basal-bolus regimen in five European countries. J Med Econ 2009;12:114-23.

58 Tunis SL, Minshall ME, Conner C, McCormick JI, Kapor J, Yale JF, et al. Cost-effectiveness of insulin detemir compared to NPH insulin for type 1 and type 2 diabetes mellitus in the Canadian payer setting: modeling analysis. Curr Med Res Opin 2009;25:1273-84.

59 Grima DT, Thompson MF, Sauriol L. Modelling cost effectiveness of insulin glargine for the treatment of type 1 and 2 diabetes in Canada. Pharmacoeconomics 2007;25:253-66.

60 McEwan PP, Poole CD, Tetlow T, Holmes P, Currie CJ. Evaluation of the cost-effectiveness of insulin glargine versus NPH insulin for the treatment of type 1 diabetes in the UK. Curr Med Res Opin 2007;23(s1):S7-19.

61 Valentine WJ, Palmer AJ, Erny-Albrecht KM, Ray JA, Cobden D, Foos V, et al. Cost-effectiveness of basal insulin from a US health system perspective: comparative analyses of detemir, glargine, and NPH. Adv Ther 2006;23:191-207.

62 Hershon KS, Blevins TC, Mayo CA, Rosskamp R. Once-daily insulin glargine compared with twice-daily NPH insulin in patients with type 1 diabetes. Endocr Pract 2004:10:10-7.

63 Tran K, Banerjee S, Li H, Noorani HZ, Mensinkai S, Dooley K, et al. Long-acting insulin analogues for diabetes mellitus: meta-analysis of clinical outcomes and assessment of costeffectiveness. Canadian Agency for Drugs and Technologies in Health, 2007 (Technology report number 92).

64 Kobayashi M, Iwamoto Y, Kaku K. 48-week randomized multicenter open-label parallel group phase 3 trial to compare insulin detemir and NPH insulin efficacy and safety in subjects with insulin-requiring diabetes mellitus in a basal-bolus regimen [Japanese, English abstract]. J Jpn Diabetes Soc 2007;50:649-63.

\section{Accepted: 22 August 2014}

\section{Cite this as: BMJ 2014;349:95459}

This is an Open Access article distributed in accordance with the Creative Commons Attribution Non Commercial (CC BY-NC 3.0) license, which permits others to distribute, remix, adapt, build upon this work non-commercially, and license their derivative works on different terms, provided the original work is properly cited and the use is non-commercial. See: http://creativecommons.org/licenses/by-nc/3.0/. 


\section{Tables}

\begin{tabular}{|c|c|c|c|c|c|c|}
\hline \multicolumn{7}{|c|}{ Table 1| Study characteristics } \\
\hline Study & $\begin{array}{l}\text { Treatment } \\
\text { period } \\
\text { (weeks) }\end{array}$ & $\begin{array}{l}\text { Sample } \\
\text { size }\end{array}$ & Country & Setting & $\begin{array}{l}\text { Treatment, comparator (daily } \\
\text { frequency) }\end{array}$ & Outcomes \\
\hline \multicolumn{7}{|c|}{ Randomized clinical trials } \\
\hline Mathiesen, ${ }^{25} 2012$ & 24 & 310 & 17 countries $^{*}$ & Multinational & $\begin{array}{l}\text { Detemir (od or bid), NPH (od or } \\
\text { bid) + aspart }\end{array}$ & $\begin{array}{c}A_{10}, \text { body weight, severe } \\
\text { hypoglycemia, mortality, } \\
\text { retinopathy }\end{array}$ \\
\hline Renard, ${ }^{26} 2011$ & 16 & 135 & France & Multicenter & $\begin{array}{l}\text { Glargine (od), detemir (od) + } \\
\text { glulisine }\end{array}$ & $\begin{array}{l}A_{10} \text {, body weight, severe } \\
\text { hypoglycemia, mortality }\end{array}$ \\
\hline Zachariah, ${ }^{27} 2011$ & 16 & 23 & UK & Single center & $\begin{array}{l}\text { NPH (od or bid), detemir (od or } \\
\text { bid) + aspart }\end{array}$ & $\begin{array}{c}A_{10}, \text { body weight, severe } \\
\text { hypoglycemia }\end{array}$ \\
\hline Heller, ${ }^{28} 2009$ & 52 & 447 & Denmark, UK, USA & Multinational & $\begin{array}{l}\text { Detemir (od or bid), glargine (od) } \\
+ \text { + aspart }\end{array}$ & $\begin{array}{c}A_{1 c}, \text { body weight, severe } \\
\text { hypoglycemia }\end{array}$ \\
\hline Le Floch, ${ }^{29} 2009$ & 16 & 512 & Belgium, France & Multinational & $\begin{array}{l}\text { Detemir (od), detemir (bid) + } \\
\text { aspart }\end{array}$ & $A_{1 c}$, body weight \\
\hline Bartley, ${ }^{30} 2008$ & 104 & 497 & $\begin{array}{l}\text { Argentina, Australia, } \\
\text { Bulgaria, Croatia, India, } \\
\text { Macedonia, Malaysia, } \\
\text { Romania, South Africa, } \\
\text { Turkey }\end{array}$ & Multinational & Detemir (od), NPH (od) + aspart & $\begin{array}{l}A_{1 c}, \text { body weight, severe } \\
\text { hypoglycemia, mortality }\end{array}$ \\
\hline Bolli, ${ }^{31} 2009$ & 24 & 175 & Italy & Multicenter & Glargine (od), NPH (od) + lispro & $\begin{array}{c}A_{10} \text {, severe hypoglycemia, } \\
\text { quality of life }\end{array}$ \\
\hline Chatterjee, ${ }^{32} 2007$ & 16 & 60 & UK & Single center & Glargine (od), NPH (bid) + aspart & $\begin{array}{c}A_{10}, \text { body weight, severe } \\
\text { hypoglycemia }\end{array}$ \\
\hline Pesic, ${ }^{33} 2007$ & 15 & 48 & Serbia & NR & $\begin{array}{c}\text { NPH (od), NPH (bid), glargine } \\
\text { (od) + aspart }\end{array}$ & $A_{10}$ \\
\hline Philippo, ${ }^{34} 2007 \dagger$ & 26 & 113 & Netherlands & Multicenter & $\begin{array}{l}\text { Detemir (od or bid), NPH (od or } \\
\text { bid) + aspart }\end{array}$ & Mortality \\
\hline Pieber, ${ }^{35} 2007$ & 26 & 322 & $\begin{array}{c}\text { Austria, Germany, South } \\
\text { Africa }\end{array}$ & Multinational & $\begin{array}{l}\text { Detemir (bid), glargine (od) }+ \\
\text { aspart }\end{array}$ & $\begin{array}{c}A_{10} \text {, body weight, hospital } \\
\text { admissions, severe } \\
\text { hypoglycemia }\end{array}$ \\
\hline Radman, ${ }^{36} 2007$ & 16 & 56 & Croatia & Single center & NPH (bid), glargine (od) + aspart & $A_{1 c}$ \\
\hline Ashwell, ${ }^{37} 2006$ & 8 & 20 & UK & Single center & Glargine (od), glargine (bid) & $\begin{array}{c}A_{10}, \begin{array}{c}\text { severe hypoglycemia, } \\
\text { mortality }\end{array} \\
\text { mats }\end{array}$ \\
\hline Kolendorf, ${ }^{38} 2006$ & 32 & 130 & $\begin{array}{c}\text { Australia, Europe, South } \\
\text { Africa }\end{array}$ & Multicenter & Detemir (bid), NPH (bid) + aspart & $\begin{array}{l}A_{1 c}, \text { body weight, severe } \\
\text { hypoglycemia, mortality }\end{array}$ \\
\hline De Leeuw, ${ }^{39} 2005$ & 24 & 315 & $\begin{array}{l}\text { Belgium, Denmark, } \\
\text { France, Netherlands, } \\
\text { Norway }\end{array}$ & Multinational & Detemir (bid), NPH (bid) + aspart & $\begin{array}{l}A_{10}, \text { body weight, severe } \\
\text { hypoglycemia }\end{array}$ \\
\hline Fulcher, ${ }^{40} 2005$ & 30 & 125 & Australia & Multicenter & Glargine (od), NPH (od) + lispro & $\begin{array}{c}A_{1 c}, \text { body weight, severe } \\
\text { hypoglycemia }\end{array}$ \\
\hline Pieber, ${ }^{41} 2005$ & 16 & 400 & $\begin{array}{l}\text { Austria, Finland, } \\
\text { Germany, Italy, Norway, } \\
\text { Poland, Switzerland }\end{array}$ & Multinational & Detemir (bid), NPH (bid) + aspart & $\begin{array}{l}A_{10} \text {, body weight, transient } \\
\text { ischemic attack }\end{array}$ \\
\hline Home, ${ }^{42} 2004$ & 16 & 408 & $\begin{array}{c}\text { Australia, Belgium, } \\
\text { Denmark, France, } \\
\text { Netherlands, Sweden, } \\
\text { UK }\end{array}$ & Multinational & Detemir (bid), NPH (bid) + aspart & $\begin{array}{c}A_{10}, \text { body weight, severe } \\
\text { hypoglycemia }\end{array}$ \\
\hline Porcellati, ${ }^{43} 2004$ & 52 & 121 & Italy & NR & NPH (qid), glargine (od) + lispro & $\begin{array}{c}A_{10}, \text { body weight, severe } \\
\text { hypoglycemia }\end{array}$ \\
\hline Russell-Jones, ${ }^{44} 2004$ & 26 & 749 & Australia, Europe & Multinational & $\begin{array}{c}\text { Detemir (od), } \mathrm{NPH}(\mathrm{od})+\text { human } \\
\text { insulin }\end{array}$ & $\begin{array}{c}\mathrm{A}_{1 \mathrm{c}}, \text { body weight, serious } \\
\text { hyperglycemia, severe } \\
\text { hypoglycemia }\end{array}$ \\
\hline Standl, ${ }^{45} 2004$ & 26 & 289 & $\begin{array}{c}\text { Australia, Austria, } \\
\text { Germany, New Zealand, } \\
\text { Switzerland }\end{array}$ & Multinational & Detemir (bid), NPH (bid) + aspart & $\begin{array}{c}A_{10}, \begin{array}{l}\text { severe hypoglycemia, } \\
\text { retinopathy }\end{array}\end{array}$ \\
\hline Rossetti, ${ }^{46} 2003$ & 12 & 51 & Italy & NR & NPH (od), glargine (od) + lispro & $A_{10}$, severe hypoglycemia \\
\hline
\end{tabular}


Table 1 (continued)

\begin{tabular}{|c|c|c|c|c|c|c|}
\hline Study & $\begin{array}{l}\text { Treatment } \\
\text { period } \\
\text { (weeks) }\end{array}$ & $\begin{array}{l}\text { Sample } \\
\text { size }\end{array}$ & Country & Setting & $\begin{array}{l}\text { Treatment, comparator (daily } \\
\text { frequency) }\end{array}$ & Outcomes \\
\hline Vague,${ }^{47} 2003$ & 26 & 448 & $\begin{array}{c}\text { France, Belgium, } \\
\text { Luxembourg, } \\
\text { Netherlands, Norway }\end{array}$ & Multinational & Detemir (bid), NPH (bid) + aspart & $\begin{array}{c}A_{10}, \text { body weight, severe } \\
\text { hypoglycemia }\end{array}$ \\
\hline Pieber, ${ }^{48} 2000$ & 4 & 333 & Europe & Multinational & $\begin{array}{l}\text { Glargine }(\text { od), NPH (od or bid) + } \\
\text { regular human insulin }\end{array}$ & $A_{1 c}$, severe hypoglycemia \\
\hline Raskin, ${ }^{49} 2000$ & 16 & 619 & Canada, USA & Multinational & $\begin{array}{c}\text { Glargine (od), NPH (od or bid) + } \\
\text { lispro }\end{array}$ & $\begin{array}{c}\mathrm{A}_{1 \mathrm{c}} \text {, body weight, cancer, } \\
\text { severe hypoglycemia, } \\
\text { mortality, retinopathy }\end{array}$ \\
\hline $\begin{array}{l}\text { Ratner, }{ }^{50} 2000 \\
\text { (CR: Hershon, }{ }^{62} 2004 \text { ) }\end{array}$ & 28 & 534 & USA & Multicenter & $\begin{array}{l}\text { Glargine (od), NPH (od or bid) + } \\
\text { regular insulin }\end{array}$ & $\begin{array}{l}A_{10} \text {, body weight, severe } \\
\text { hypoglycemia, mortality }\end{array}$ \\
\hline Rosenstock,,$^{51} 2000$ & 4 & 256 & USA & NR & $\begin{array}{l}\text { Glargine (od), NPH (od or bid) + } \\
\text { human insulin }\end{array}$ & A1c \\
\hline \multicolumn{7}{|l|}{ Cohort study } \\
\hline Currie, ${ }^{52} 2007$ & 783 & 3142 & UK & Multicenter & Glargine, detemir & A1c, body weight \\
\hline \multicolumn{7}{|c|}{ Cost effectiveness studies } \\
\hline Pfohl, ${ }^{53} 2012$ & NR & NR & Germany & Single country & Glargine, NPH & QALY, life years \\
\hline Valentine,$^{54} 2012$ & NR & NR & $\begin{array}{l}\text { Denmark, Finland, } \\
\text { Netherlands, Sweden }\end{array}$ & Multinational & Detemir, NPH & QALY \\
\hline Valentine,$^{55} 2011$ & NR & 497 & Sweden & Single country & Detemir (od), NPH (od) & QALY, life years \\
\hline Cameron, ${ }^{5} 2009$ & NR & NR & Canada & Single country & Detemir, glargine, NPH & QALY \\
\hline Greiner, ${ }^{56} 2009 \dagger$ & NR & NR & Switzerland & Single country & Glargine, NPH & QALY, life years \\
\hline Gschwend, ${ }^{57} 2009$ & NR & 497 & $\begin{array}{c}\text { Belgium, France, } \\
\text { Germany, Italy, Spain }\end{array}$ & Multinational & Detemir (od), NPH (od) & QALY \\
\hline Tunis, $^{58} 2009$ & NR & 497 & Canada & Single country & Detemir, NPH & QALY, life years \\
\hline Grima, ${ }^{59} 2007$ & NR & NR & Canada & Single country & Glargine, NPH & QALY, life years \\
\hline McEwan, ${ }^{60} 2007$ & NR & NR & UK & Single country & Glargine, NPH & QALY \\
\hline Valentine,$^{61} 2006$ & NR & 598 & USA & Single-country & Detemir (bid), glargine (od) & QALY, life years \\
\hline
\end{tabular}

$A_{1 c}=$ glycated hemoglobin; bid=twice daily; $N P H=$ neutral protamine Hagedorn; $N R=$ not reported; od=once daily; QALY=quality adjusted life years; qid=four times daily.

*Argentina, Australia, Austria, Brazil, Canada, Croatia, Denmark, Finland, France, Ireland, Israel, Norway, Poland, Russia, South Africa, Spain, UK. †Unpublished data. 


\begin{tabular}{|c|c|c|c|}
\hline \multicolumn{4}{|c|}{ Table 2| Summary of results from direct pairwise and network meta-analysis from randomized clinical trials } \\
\hline \multirow[b]{2}{*}{ Treatment comparison } & \multirow{2}{*}{$\begin{array}{l}\text { No of studies in } \\
\text { direct MA }\end{array}$} & \multicolumn{2}{|c|}{ Effect size $(95 \% \mathrm{Cl})$} \\
\hline & & Direct estimate & NMA estimate \\
\hline \multicolumn{4}{|c|}{$A_{1 c}$ in $\%(26$ RCTs including 6776 patients contributing to NMA): MD (95\% Cl) } \\
\hline $\mathrm{NPH}$ (qid) $v \mathrm{NPH}$ (od/bid) & NA & NA & $0.32(-0.15$ to 0.79$)$ \\
\hline $\mathrm{NPH}(\mathrm{od}) v \mathrm{NPH}$ (od/bid) & 1 & $0.69(0.21$ to 1.17$)$ & $0.31(0.02$ to 0.60$)$ \\
\hline Detemir (od/bid) $v$ NPH (od/bid) & 8 & $-0.04(-0.12$ to 0.03$)$ & $-0.05(-0.28$ to 0.18$)$ \\
\hline Detemir (qid) $v \mathrm{NPH}(\mathrm{od} / \mathrm{bid})$ & NA & NA & $-0.07(-0.54$ to 0.39$)$ \\
\hline Detemir (od) $v \mathrm{NPH}$ (od/bid) & NA & NA & $0.05(-0.25$ to 0.36$)$ \\
\hline Glargine (bid) $v$ NPH (od/bid) & NA & NA & $-0.08(-0.54$ to 0.39$)$ \\
\hline Glargine (od) $v$ NPH (od/bid) & 7 & $-0.08(-0.19$ to 0.02$)$ & $-0.08(-0.32$ to 0.16$)$ \\
\hline $\mathrm{NPH}$ (od) $v \mathrm{NPH}$ (qid) & NA & NA & $-0.01(-0.46$ to 0.44$)$ \\
\hline Detemir (od/bid) $v$ NPH (qid) & NA & NA & $-0.37(-0.84$ to 0.10$)$ \\
\hline Detemir (qid) $v$ NPH (qid) & NA & NA & $-0.40(-0.96$ to 0.17$)$ \\
\hline Detemir (od) $v \mathrm{NPH}$ (qid) & NA & NA & $-0.27(-0.73$ to 0.20$)$ \\
\hline Glargine (bid) $v$ NPH (qid) & NA & NA & $-0.40(-0.97$ to 0.17$)$ \\
\hline Glargine (od) $v \mathrm{NPH}$ (qid) & 1 & $-0.40(-0.68$ to -0.12$)$ & $-0.40(-0.80$ to 0.00$)$ \\
\hline Detemir (od/bid) v NPH (od) & NA & NA & $-0.36(-0.65$ to -0.08$)$ \\
\hline Detemir (qid) $v \mathrm{NPH}(\mathrm{od})$ & NA & NA & $-0.39(-0.83$ to 0.06$)$ \\
\hline Detemir (od) $v$ NPH (od) & 2 & $-0.16(-0.30$ to -0.03$)$ & $-0.26(-0.48$ to -0.03$)$ \\
\hline Glargine (bid) $v \mathrm{NPH}$ (od) & NA & NA & $-0.39(-0.84$ to 0.06$)$ \\
\hline Glargine (od) $v$ NPH (od) & 4 & $-0.50(-0.87$ to -0.13$)$ & $-0.39(-0.59$ to -0.19$)$ \\
\hline Detemir (qid) $v$ detemir (od/bid) & NA & NA & $-0.02(-0.49$ to 0.45$)$ \\
\hline Detemir (od) $v$ detemir (od/bid) & 1 & $0.10(-0.06$ to 0.26$)$ & $0.11(-0.17$ to 0.38$)$ \\
\hline Glargine (bid) $v$ detemir (od/bid) & NA & NA & $-0.03(-0.50$ to 0.45$)$ \\
\hline Glargine (od) $v$ detemir (od/bid) & 1 & $0.03(-0.20$ to 0.26$)$ & $-0.03(-0.27$ to 0.22$)$ \\
\hline Detemir (od) $v$ detemir (qid) & NA & NA & $0.13(-0.34$ to 0.59$)$ \\
\hline Glargine (bid) $v$ detemir (qid) & NA & NA & $0.00(-0.57$ to 0.57$)$ \\
\hline Glargine (od) $v$ detemir (qid) & 1 & $-0.01(-0.18$ to 0.16$)$ & $-0.01(-0.41$ to 0.40$)$ \\
\hline Glargine (bid) $v$ detemir (od) & NA & NA & $-0.13(-0.60$ to 0.34$)$ \\
\hline Glargine (od) $v$ detemir (od) & 1 & $0.04(-0.17$ to 0.25$)$ & $-0.13(-0.37$ to 0.10$)$ \\
\hline Glargine (od) $v$ glargine (bid) & 1 & $0.00(-0.28$ to 0.28$)$ & $0.00(-0.41$ to 0.40$)$ \\
\hline \multicolumn{4}{|c|}{ Body weight in $\mathrm{kg}$ (13 RCTs including 4462 patients contributing to NMA): MD (95\% Cl) } \\
\hline $\mathrm{NPH}(\mathrm{od}) v \mathrm{NPH}$ (od/bid) & NA & NA & 4.64 (3.53 to 5.75$)$ \\
\hline Detemir (od/bid) $v$ NPH (od/bid) & 5 & $-0.96(-1.52$ to -0.39$)$ & $-0.87(-1.44$ to -0.30$)$ \\
\hline Detemir (od) $v \mathrm{NPH}$ (od/bid) & NA & NA & 4.04 (3.06 to 5.02$)$ \\
\hline Glargine (od) $v$ NPH (od/bid) & 3 & $-0.38(-0.74$ to -0.03$)$ & $-0.50(-1.11$ to 0.11$)$ \\
\hline Detemir (od/bid) v NPH (od) & NA & NA & $-5.51(-6.56$ to -4.46$)$ \\
\hline Detemir (od) $v$ NPH (od) & 2 & $-0.85(-1.65$ to -0.04$)$ & $-0.60(-1.13$ to -0.08$)$ \\
\hline Glargine (od) $v \mathrm{NPH}(\mathrm{od})$ & NA & NA & $-5.14(-6.07$ to -4.21$)$ \\
\hline Detemir (od) $v$ detemir (od/bid) & NA & NA & 4.91 (4.00 to 5.81$)$ \\
\hline Glargine (od) $v$ detemir (od/bid) & 2 & $0.30(-0.23$ to 0.83$)$ & $0.37(-0.11$ to 0.85$)$ \\
\hline Glargine (od) $v$ detemir (od) & 1 & $-4.50(-10.10$ to 1.10$)$ & $-4.54(-5.30$ to -3.77$)$ \\
\hline \multicolumn{4}{|c|}{ Severe hypoglycemia (16 RCTs including 5797 patients contributing to NMA): OR (95\% Cl) } \\
\hline $\mathrm{NPH}(\mathrm{od}) v \mathrm{NPH}(\mathrm{od} / \mathrm{bid})$ & & & 0.46 (0.08 to 2.57$)$ \\
\hline Detemir (od/bid) $v$ NPH (od/bid) & 6 & $0.68(0.52$ to 0.89$)$ & $0.62(0.42$ to 0.91$)$ \\
\hline Detemir (qid) $v$ NPH (od/bid) & NA & NA & $1.02(0.35$ to 2.97$)$ \\
\hline Detemir (od) $v$ NPH (od/bid) & NA & NA & $0.27(0.06$ to 1.36$)$ \\
\hline Glargine (bid) $v \mathrm{NPH}$ (od/bid) & NA & NA & $0.09(0.00$ to 1.97$)$ \\
\hline Glargine (od) $v$ NPH (od/bid) & 4 & $0.48(0.21$ to 1.10$)$ & $0.61(0.30$ to 1.23$)$ \\
\hline
\end{tabular}


Table 2 (continued)

\begin{tabular}{|c|c|c|c|}
\hline \multirow[b]{2}{*}{ Treatment comparison } & \multirow{2}{*}{$\begin{array}{l}\text { No of studies in } \\
\text { direct MA }\end{array}$} & \multicolumn{2}{|c|}{ Effect size $(95 \% \mathrm{Cl})$} \\
\hline & & Direct estimate & NMA estimate \\
\hline Detemir (od/bid) v NPH (od) & NA & NA & 1.34 (0.24 to 7.66$)$ \\
\hline Detemir (qid) $v \mathrm{NPH}$ (od) & NA & NA & 2.19 (0.38 to 12.68$)$ \\
\hline Detemir (od) $v$ NPH (od) & 2 & $0.58(0.40$ to 0.83$)$ & $0.59(0.32$ to 1.09$)$ \\
\hline Glargine (bid) $v$ NPH (od) & NA & NA & 0.19 (0.01 to 5.70$)$ \\
\hline Glargine (od) $v \mathrm{NPH}$ (od) & NA & NA & $1.30(0.27$ to 6.21$)$ \\
\hline Detemir (qid) $v$ detemir (od/bid) & NA & NA & $1.63(0.53$ to 5.01$)$ \\
\hline Detemir (od) $v$ detemir (od/bid) & NA & NA & $0.44(0.09$ to 2.26$)$ \\
\hline Glargine (bid) $v$ detemir (od/bid) & NA & NA & 0.14 (0.01 to 3.22$)$ \\
\hline Glargine (od) $v$ detemir (od/bid) & 1 & 4.30 (1.19 to 15.53$)$ & 0.97 (0.45 to 2.12$)$ \\
\hline Detemir (od) $v$ detemir (qid) & NA & NA & $0.27(0.05$ to 1.40$)$ \\
\hline Glargine (bid) $v$ detemir (qid) & NA & NA & 0.08 (0.00 to 1.98$)$ \\
\hline Glargine (od) $v$ detemir (qid) & 1 & $0.59(0.40$ to 0.89$)$ & $0.59(0.27$ to 1.33$)$ \\
\hline Glargine (bid) $v$ detemir (od) & NA & NA & 0.31 (0.01 to 9.12$)$ \\
\hline Glargine (od) $v$ detemir (od) & 1 & 2.21 (0.63 to 7.77 ) & 2.21 (0.52 to 9.28$)$ \\
\hline Glargine (od) $v$ glargine (bid) & 1 & 7.04 (0.36 to 136.99$)$ & 7.04 (0.33 to 148.45$)$ \\
\hline
\end{tabular}

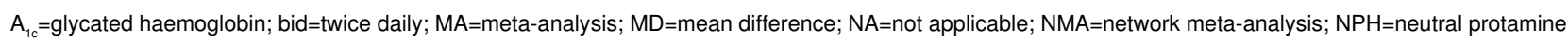
Hagedorn; od=once daily; $O R=o d d s$ ratio; qid=four times daily. 


\begin{tabular}{|c|c|c|c|c|c|c|}
\hline Study & Currency, year & Perspective & Effect & $\Delta \mathbf{C}^{*}$ & $\Delta \mathrm{E}$ & Exact ICER ${ }^{*}$ \\
\hline \multicolumn{7}{|c|}{ Detemir versus NPH } \\
\hline \multirow[t]{4}{*}{ Valentine ${ }^{54} 2012$} & Euro, 2010 & $\begin{array}{l}\text { Public healthcare payer, } \\
\text { Denmark }\end{array}$ & QALY & 68.35 & 0.02 & 3418 \\
\hline & Euro, 2010 & Public healthcare payer, Sweden & QALY & 69.09 & 0.02 & 3455 \\
\hline & Euro, 2010 & Public healthcare payer, Finland & QALY & 88.04 & 0.02 & 4402 \\
\hline & Euro, 2010 & Healthcare payer, Netherlands & QALY & 63.24 & 0.02 & 3162 \\
\hline \multirow[t]{2}{*}{ Valentine, ${ }^{55} 2011$} & Swedish Krnor, 2006 & Public healthcare payer & QALY & 4329.38 & 0.53 & 8169 \\
\hline & Swedish Krnor, 2006 & Public healthcare payer & Life years & 4329.38 & 0.14 & $30924 \dagger$ \\
\hline Cameron, ${ }^{5} 2009$ & Canadian, 2007 & Public healthcare payer & QALY & 3718.61 & 0.01 & 371861 \\
\hline \multirow[t]{5}{*}{ Gschwend, ${ }^{57} 2009$} & Euro, 2006 & Third party payer, Belgium & QALY & -18300.85 & 0.52 & -35194 \\
\hline & Euro, 2006 & Third party payer, France & QALY & 435.22 & 0.55 & 791 \\
\hline & Euro, 2006 & Third party payer, Germany & QALY & -1308.74 & 0.45 & -2908 \\
\hline & Euro, 2006 & Third party payer, Italy & QALY & 2907.11 & 0.59 & 4927 \\
\hline & Euro, 2006 & Third party payer, Spain & QALY & -882.71 & 0.40 & -2207 \\
\hline \multirow[t]{2}{*}{ Tunis, ${ }^{58} 2009$} & Canadian dollars, 2007 & Public healthcare payer & QALY & 9935.13 & 0.48 & 20698 \\
\hline & Canadian dollars, 2007 & Public healthcare payer & Life years & 9935.13 & 0.05 & $198703 \dagger$ \\
\hline \multicolumn{7}{|c|}{ Glargine versus NPH } \\
\hline \multirow[t]{2}{*}{ Pfohl,${ }^{53} 2012$} & Euro, 2010 & Public healthcare payer & QALY & -14823188.10 & 793 & -18693 \\
\hline & Euro, 2010 & Public healthcare payer & Life years & -14823188.10 & 392 & $-37914 \dagger$ \\
\hline Cameron, ${ }^{5} 2009$ & Canadian dollars, 2007 & Public healthcare payer & QALY & 2930.21 & 0.04 & 73255 \\
\hline \multirow[t]{2}{*}{ Greiner, ${ }^{56} 2009 \ddagger$} & $\mathrm{CHF}, 2006$ & NR & QALY & 1437.71 & 0.24 & 5990 \\
\hline & CHF, 2006 & NR & Life years & 1437.71 & 0.06 & 23962 \\
\hline \multirow[t]{2}{*}{ Grima, $^{59} 2007$} & Canadian dollars, 2005 & Public healthcare payer & QALY & 1426.06 & 0.07 & 20372 \\
\hline & Canadian dollars, 2005 & Public healthcare payer & Life years & 1426.06 & 0.08 & $17826 \dagger$ \\
\hline McEwan, ${ }^{60} 2007$ & UK pounds, 2005 & Public healthcare payer & & 2534.14 & 0.13 & 19493 \\
\hline \multicolumn{7}{|c|}{ Glargine versus detemir } \\
\hline \multirow[t]{2}{*}{ Valentine ${ }^{61} 2006$} & US dollars, 2005 & Societal & QALY & 6563.69 & -0.06 & -109395 \\
\hline & US dollars, 2005 & Societal & Life years & 6563.69 & -0.09 & $-72930 \dagger$ \\
\hline
\end{tabular}

$\Delta \mathrm{C}=$ difference in cost between treatment and control; $\Delta \mathrm{E}=$ difference in effectiveness between treatment and control; ICER=incremental cost effectiveness ratio; $\mathrm{NPH}=$ neutral protamine Hagedorn; NR=not reported; $\mathrm{QALY}=$ quality adjusted life years.

*In US dollars, 2012.

†ICER was derived.

‡Unpublished data. 


\section{Figures}

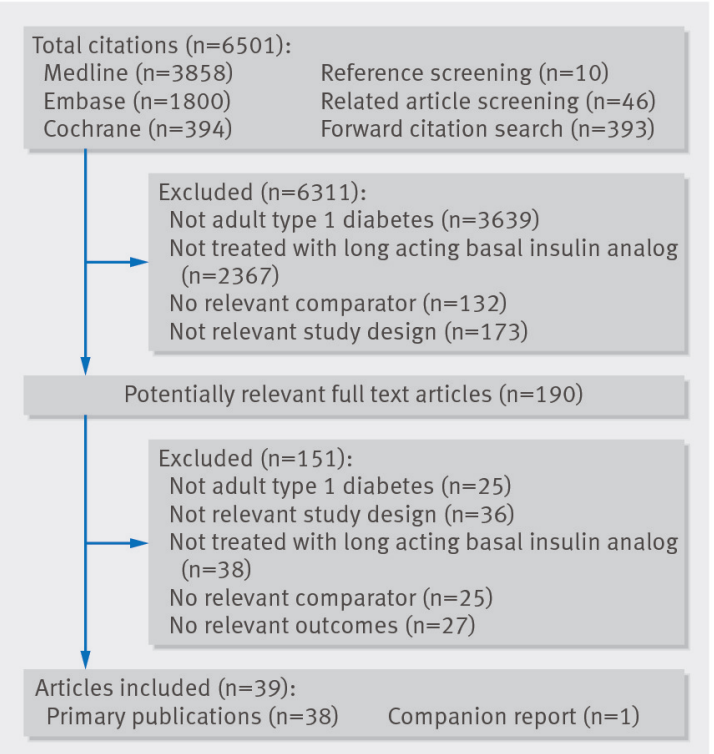

Fig 1 Study flow

Treatment comparison

NPH (qid) $v$ NPH (od/bid) NPH (od) $v$ NPH (od/bid) Detemir (od/bid) $v$ NPH (od/bid) Detemir (qid) $v$ NPH (od/bid) Detemir (od) $v$ NPH (od/bid) Glargine (bid) $v$ NPH (od/bid) Glargine (od) $v$ NPH (od/bid) $\mathrm{NPH}$ (od) $v$ NPH (qid) Detemir (od/bid) $\vee$ NPH (qid) Detemir (qid) $v$ NPH (qid) Detemir (od) $\vee$ NPH (qid) Glargine (bid) $v \mathrm{NPH}$ (qid) Glargine (od) $v$ NPH (qid) Detemir (od/bid) $\vee$ NPH (od) Detemir (qid) $v$ NPH (od) Detemir (od) $v$ NPH (od) Glargine (bid) $v$ NPH (od) Glargine (od) $v$ NPH (od) Detemir (qid) $v$ detemir (od/bid) Detemir (od) $v$ detemir (od/bid) Glargine (bid) $v$ detemir (od/bid) Glargine (od) $v$ detemir (od/bid) Detemir (od) $v$ detemir (qid) Glargine (bid) $v$ detemir (qid) Glargine (od) $v$ detemir (qid) Glargine (bid) $v$ detemir (od) Glargine (od) $v$ detemir (od) Glargine (od) $v$ glargine (bid)

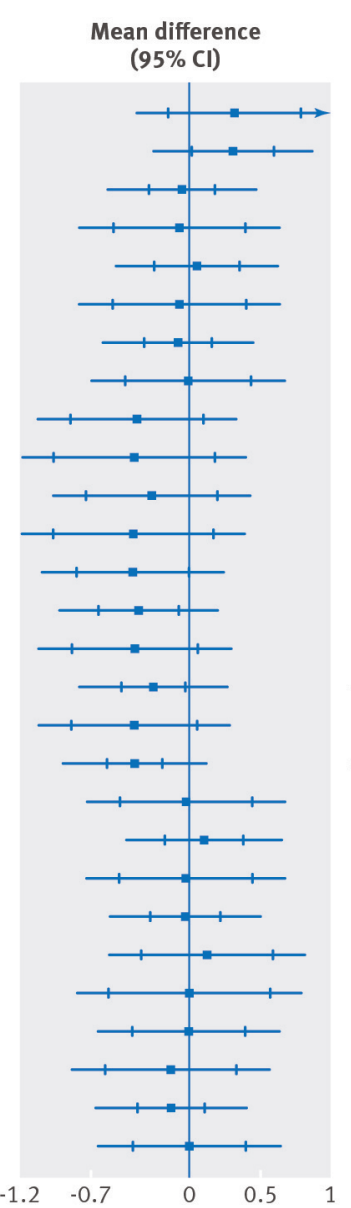

Mean difference $\quad 95 \%$ predictive $(95 \% \mathrm{Cl}) \quad$ interval

$0.32(-0.15$ to 0.79$) \quad(-0.38$ to 1.02$)$ 0.31 (0.02 to 0.60$) \quad(-0.25$ to 0.87$)$ -0.05 (-0.28 to 0.18$) \quad(-0.58$ to 0.47$)$ $-0.07(-0.54$ to 0.39$) \quad(-0.77$ to 0.62$)$ 0.05 (-0.25 to 0.36$) \quad$ (-0.52 to 0.62$)$ -0.08 (-0.54 to 0.39$) \quad(-0.78$ to 0.62$)$ $-0.08(-0.32$ to 0.16$) \quad(-0.61$ to 0.45$)$ -0.01 (-0.46 to 0.44$) \quad(-0.69$ to 0.67$)$ $-0.37(-0.84$ to 0.10$) \quad(-1.07$ to 0.33$)$ -0.40 (-0.96 to 0.17$) \quad(-1.18$ to 0.39$)$ $-0.27(-0.73$ to 0.20$) \quad(-0.96$ to 0.43$)$ $-0.40(-0.97$ to 0.17$) \quad(-1.19$ to 0.39$)$ $-0.40(-0.80$ to 0.00$) \quad(-1.04$ to 0.24$)$ $-0.36(-0.65$ to -0.08$) \quad(-0.92$ to 0.20$)$ $-0.39(-0.83$ to 0.06$) \quad(-1.07$ to 0.29$)$ -0.26 (-0.48 to -0.03$) \quad(-0.78$ to 0.26$)$ -0.39 ( -0.84 to 0.06$) \quad(-1.07$ to 0.29$)$ $-0.39(-0.59$ to -0.19$) \quad(-0.90$ to 0.12$)$ $-0.02(-0.49$ to 0.45$) \quad(-0.72$ to 0.68$)$ 0.11 ( -0.17 to 0.38$) \quad(-0.45$ to 0.66$)$ $-0.03(-0.50$ to 0.45$) \quad(-0.73$ to 0.68$)$ $-0.03(-0.27$ to 0.22$) \quad(-0.56$ to 0.51$)$ 0.13 (-0.34 to 0.59$) \quad(-0.57$ to 0.83$)$ $0.00(-0.57$ to 0.57$) \quad(-0.79$ to 0.79$)$ -0.01 (-0.41 to 0.40$) \quad(-0.65$ to 0.64$)$ $-0.13(-0.60$ to 0.34$) \quad(-0.83$ to 0.57$)$ $-0.13(-0.37$ to 0.10$) \quad(-0.66$ to 0.39$)$ $0.00(-0.41$ to 0.40$) \quad(-0.65$ to 0.64$)$

Fig 2 Network meta-analysis estimates for glycated hemoglobin (26 randomized clinical trials including 6776 patients). bid=twice daily; od=once daily; qid=four times daily 